\title{
Marcas corporais na adolescência: (im)possibilidades de simbolização
}

(Body marks in adolescence: (im)possibilities of symbolic representation)

(Marcas corporales en la adolescencia: (im) posibilidades de simbolización)

\author{
Mônica Medeiros Kother Macedo* \\ Adriana Silveira Gobbi** \\ Evelise Machado Pinto Waschburger***
}

\begin{abstract}
Resumo
$\mathrm{Na}$ adolescência, o corpo é tomado por intensas modificações biológicas e psíquicas que podem ser equiparadas a uma vivência de invasão. $\mathrm{O}$ trabalho psíquico próprio da adolescência encontra no corpo um cenário privilegiado de expressão. Objetiva-se, neste artigo, por meio das contribuiçôes da Psicanálise, propor uma leitura de problemáticas da adolescência nas quais a busca por marcas corporais pode expressar as (im)possibilidades de simbolização das conflitivas próprias dessa etapa. Dessa maneira, as expressões no corpo são abordadas não apenas como recursos de elaboraçãao do excesso, próprio da experiência de ressignificação da adolescência, mas, principalmente, como manifestações que podem revelar o fracasso desse processo. $\mathrm{O}$ uso de tatuagens e piercings, circunscritos ao contexto adolescente, é abordado com o intuito de enfatizar que essas marcas corporais ocorrem simultaneamente às intensas transformaçôes da adolescência. Esses fenômenos são abordados, privilegiandose a singularidade dessa idade da vida.
\end{abstract}

Palavras-chave: adolescência; corpo; psicanálise; tatuagens; piercings.

\begin{abstract}
During adolescence, the body is affected by intense biological and psychological changes that can be compared to a kind of invasion experience. The psychic work inherent to adolescence finds a privileged scenario for expression in the body. Based on contributions of psychoanalysis, this article proposes a possible interpretation of problems typical of adolescence, in which the search for body marks and traces can express (im)possibilities of symbolic conflicts inherent
\end{abstract}

\footnotetext{
* Texto recebido em agosto/2008 e aprovado para publicação em janeiro/2009.

Psicóloga, psicanalista, doutora em Psicologia/PUCRS, e-mail: monicakm@pucrs.br

** Psicóloga, mestre em Psicologia Clínica pelo Programa de Pós-Graduação da PUCRS, e-mail: adrianagobbi@terra.com.br

*** Psicóloga, mestranda em Psicologia Clínica pelo Programa de Pós-Graduação da PUCRS, e-mail: evelisew@terra. com.br
} 
to that period of life. Thus, body expressions are approached not only as resources for the elaboration of excess, characteristic of the experience of resignifying in adolescence, but mainly as manifestations which can reveal a sort of failure in the process. The use of tattoos and piercing is approached in order to emphasize that these body marks come together with the intense changes that occur during adolescence. The investigation of those phenomena takes into account the uniqueness of that period of life.

Keywords: adolescence; body; psychoanalysis, tattoos, piercing.

\section{Resumen}

En la adolescencia el cuerpo es tomado por intensas modificaciones biológicas y psíquicas que pueden ser comparables a una vivencia de invasión. El trabajo psíquico propio de la adolescencia encuentra en el cuerpo un escenario privilegiado de expresión. Este artículo, tiene por objetivo proponer, por medio de contribuciones del psicoanálisis, un abordaje de problemáticas de la adolescencia, en las cuales la búsqueda por marcas corporales pueden expresar las (im) posibilidades de simbolización de las conflictivas. Las expresiones en el cuerpo son abordadas no sólo como recursos de elaboración del exceso, propio de la experiencia de resignificación de la adolescencia, sino también, y principalmente, como manifestaciones que revelan el fracaso de este proceso. El uso de tatuajes y piercings, circunscritos al contexto adolescente, es abordado con el objetivo de enfatizar que estas marcas corporales ocurren simultáneamente con intensas transformaciones. Estos fenómenos son abordados privilegiándose la singularidad de esta etapa de la vida.

Palabras-clave: adolescencia; cuerpo; Psicoanálisis; tatuajes; piercings.

$\mathrm{Na}$ ficção, na realidade, seja lá onde for, a produção do corpo sempre esteve presente em nós humanos. Onde estamos, sempre produzimos corpos. Somos nossos corpos (Keil, 2004, p. 157).

\section{Introdução}

a adolescência, o tema central que o jovem depara é o da ressignificação de \sua identidade. $\mathrm{O}$ adolescente precisa lidar com as intensas mudanças físicas e psíquicas as quais terão, inevitavelmente, efeitos em sua inserção social, política e cultural. Portanto, a adolescência é uma idade da vida que reúne a experiência de rompimento em relação ao tempo infantil e o movimento em direção ao crescimento, a um tempo futuro. Esses movimentos psíquicos serão extremamente importantes no sentido de 
viabilizar o desprendimento do já vivido e o acesso àquilo que é desejado, mas também desconhecido e temido. Assim, é preciso renunciar, perder algo, para adentrar nesse novo território.

Esses movimentos da adolescência podem ser comparados à ideia de desacomodação. O verbo desacomodar é formado por des + acomodar e significa "tirar dos cômodos, do lugar, desalojar, desorganizar e desordenar" (Ferreira, 1975, p. 542). A desacomodação necessária e intrínseca à vivência da adolescência possibilita, ao aliar-se à capacidade de reorganização, situar o já vivido em espaços que não impeçam e, ao contrário, estimulem, a busca pelo novo.

Dessa maneira, também, na literatura sobre a adolescência são percebidos novos ordenamentos teóricos no que diz respeito à compreensão da complexidade que envolve esse momento da vida. A fim de entender as intensas transformações do processo adolescente, a teoria psicanalítica da adolescência precisa, também, desacomodar-se, abrindo espaços novos de questionamentos diante das imposiçóes da clínica. Uma teoria precisa manter-se aberta a fim de garantir sua vigência, desde seus fundamentos, de sua capacidade interrogativa diante dos diversos e complexos fenômenos humanos.

A adolescência foi abordada, em diversos momentos, a partir da temática da elaboração dos lutos. Essa proposição, amplamente difundida na América Latina (Aberastury; Knobel, 1992), passa a ser questionada por psicanalistas como Urribarri (2003) e Viglietti (2000). Em síntese, os autores apontam a preocupação de equiparar e, portanto, reduzir a adolescência a um trabalho de luto. Nas contribuições que traz a leitura psicanalítica do fenômeno adolescente, Viglietti (2000), desde suas experiências clínicas com adolescentes, refere concordar com as proposições de que, na adolescência, ocorre um trabalho de elaborações e de simbolizações, mas discorda de que esse trabalho seja denominado trabalho de luto. A partir de uma proposta que enfatiza a ocorrência de um trabalho de luto na adolescência, corre-se o risco de enfatizar apenas a tarefa adolescente de fazer algo com o que já foi perdido. Nessa modalidade de compreensão da adolescência, Viglietti (2000) evidencia a difícil tarefa que é proposta ao adolescente, uma vez que deve definir quem é e o que é, e isso ocorre "em um mundo que o define por aquilo que não é. Definir que a problemática central da adolescência é a do luto pelo que se perdeu é uma das formas de definir o adolescente por aquilo que não é mais" (p. 51).

$\mathrm{Na}$ mesma direção, em relação à passagem da infância para a 
adolescência, Urribarri (2003) destaca ser esse um período de mudanças e transformações e não de perdas. Considera o autor em relação ao adolescente, que "se lhe custa deixar o infantil, deseja ardosamente o novo e luta para conseguilo [...], ou seja, o infantil se modifica, se complexifica e se organiza sobre nova forma [...] que, de alguma forma, inclui a anterior" (p. 54). Mesmo que ocorram renúncias a aspectos relativos ao infantil, segundo Urribarri (2003), isso não significa que o adolescente irá enlutar-se, enfatizando que a dinâmica do processo de luto, como proposta por Freud, difere significativamente do processo pelo qual vive o adolescente. Para Freud (1917/1990), o trabalho de luto implica uma falta de interesse no mundo externo que absorve o Eu do sujeito, fazendo com que o mundo torne-se pobre e vazio. Já para Urribarri (2003), na adolescência, faz-se presente um outro processo, nomeado por ele como desidealização. Nesse sentido, o adolescente desidealiza, tanto o que idealizava da condição adolescente quanto o que idealizava em relação aos pais. Assim, propõe o autor, que deve ocorrer um processo de ressignificação do que, realmente, é ser adolescente e da relação com os pais. Crescer implica ressignificar e renunciar a onipotência infantil, sendo que a compensação é ascender ao prazer e às prerrogativas dos adultos. Nessa linha de raciocínio a respeito da dinâmica da adolescência, fica evidenciado um processo de ressignificação de experiências e não apenas de elaboração de lutos.

Uma interessante abordagem da questão da adolescência é descrita por Rassial (1995), ao referir o que nomeia como o comportamento paradoxal do adolescente. $\mathrm{O}$ autor propóe considerar o caráter de ensaio que se faz presente nos atos do adolescente, destacando ser esse um recurso utilizado "na passagem entre o autoerotismo da criança e a relação de objeto adulto" (p. 28). Assim, as aparentes contradições do adolescente seriam ensaios em relação à sua inscrição no campo simbólico. Pode-se, portanto, propor uma leitura da adolescência por meio do uso desse recurso de ensaio. Assim, mediante esses comportamentos, o adolescente tenta dar conta desse importante trabalho psíquico de ressignificação que lhe é imposto pelas profundas transformações a que se vê submetido nesse momento.

O trabalho psíquico próprio da adolescência encontra no corpo um cenário privilegiado de expressão. Busca-se, então, neste artigo, por meio das contribuições da Psicanálise, realizar um estudo teórico das problemáticas da adolescência nas quais as marcas corporais expressam as (im)possibilidades de simbolização desses conflitos. São abordadas as expressões no corpo não apenas como recursos de elaboração desse excesso psíquico, próprio da experiência de ressignificação da adolescência, mas, principalmente, como manifestaçōes, via atos no corpo, do fracasso desse processo. 


\section{Aportes da Psicanálise: o corpo erógeno}

Freud (1894/1990), na tentativa de compreensão da patologia histérica, começa a questionar e investigar a etiologia de manifestações somáticas, atribuindo-lhes, posteriormente, uma etiologia psíquica. O estudo da histeria possibilitou uma nova compreensão das expressões do psíquico no corpo. De fato, Freud (1894/1990) busca aquilo que está além do corpo, mas sem desqualificá-lo como elemento de ligação entre o biológico e o psíquico. Assim, o corpo priorizado na escuta psicanalítica é o corpo libidinizado pela relação com o outro (Falcão; Krug; Macedo, 2002a).

Em seu texto Projeto para uma Psicologia cientifica, Freud (1950 [1895]/1990) postula que o ser humano nasce em estado de desamparo e, sendo assim, depende de outro humano que supra as necessidades básicas para manutenção da vida; o que denominou de ajuda alheia. Nesse mesmo texto, ao tratar da experiência de satisfação, Freud (1950 [1895]/1990) aponta que as primeiras vivências de satisfação se relacionam a uma ação especifica que suprime, pelo menos momentaneamente, o desprazer. Dessa maneira, os primeiros contatos entre o bebê e o seu cuidador estão permeados pela sensação de necessidade, por parte do bebê, e pela tarefa de satisfazer essa necessidade, via ação específica, que é de responsabilidade do cuidador. Enquanto a demanda é atendida via ajuda alheia, ocorre uma troca simbólica e, consequentemente, há o progressivo registro dessa troca - que não é apenas uma satisfação instintual - em uma ordem simbólica (Garcia-Roza, 1999).

A ação específica promove o apaziguamento da sensação de desprazer e, portanto, por meio da repetição dessa ação, uma marca mnêmica relativa à vivência de satisfação é fixada. Essa vivência será buscada toda vez que o psiquismo estiver diante do desprazer. O psiquismo tende a livrar-se da dor, buscando reativar as marcas de prazer vinculadas à vivência de satisfação. Quando o objeto da ação específica está ausente, o psiquismo, em um primeiro momento, usará o recurso da realização alucinatória do desejo, apaziguando, por algum tempo, o desprazer. Posteriormente, com a introdução dos processos de pensamento, o psiquismo será capaz de postergar a descarga. De qualquer modo, o que se salienta nesses momentos iniciais é a impossibilidade do bebê de apaziguar, por si próprio, o excesso ao qual se vê submetido. A relação com o outro cria condiçôes de, posteriormente, encontrar em si esses recursos.

Ao descrever a importância e a dinâmica desses primeiros contatos entre a criança e a mãe, Freud (1905/1990), em Três ensaios sobre a teoria da sexualidade, introduz a noção de apoio - Anlehnung. Para Freud (1905/1990), "a atividade sexual apoia-se primeiramente numa das funções que servem à 
preservação da vida e só depois se torna independente delas" (p. 170). Ou seja, inicialmente, o prazer (sexual) está vinculado à função biológico-vital, sendo que somente é possível falar de pulsão sexual a partir da independência do prazer em relação à função corporal.

Essa noção de apoio permanece vigente na conceitualização da Primeira Teoria das Pulsões - enunciada por Freud em 1910, no texto A concepção psicanalítica da perturbação psicogênica da visão, designando a relação originária das duas grandes espécies de pulsões: pulsões sexuais e pulsões de autoconservação. Em Os instintos e suas vicissitudes, Freud (1915/1990) explicita sua concepção acerca da gênese da sexualidade: "em sua primeira aparição, elas [as pulsões sexuais] se apoiam na autoconservação, das quais somente aos poucos se desligam" (p. 146). Ou seja, no contexto teórico da Primeira Tópica, a sexualidade nasce apoiada no funcionamento das atividades corporais necessárias à conservação da vida.

No espaço da sexualidade afirma-se a importância das zonas erógenas as quais abrem para o corpo um novo território, o do desejo sexual. Esse território sofrerá seu mais impactante abalo com o advento da puberdade. Esta trará novamente à cena a necessidade de novos enlaces ou desenlaces no que diz respeito ao que agora é da ordem psíquica e não mais apenas da autoconservação.

Em Três ensaios sobre a teoria da sexualidade, Freud (1905/1990) aborda a temática da adolescência, sob a denominação de puberdade. Na terceira parte da obra, denominada As transformaçôes da puberdade, Freud (1905/1990) ressalta que a vida sexual está presente desde a infância, ou seja, o que se edifica nas fases precedentes à adolescência segue ativo dentro do sujeito por toda a vida. Sendo assim, a sexualidade surge muito antes do acontecimento da puberdade. A puberdade e a adolescência constituirão um outro tempo, o da genitalidade nascente, "que se inscreve sobre um fundo de psicossexualidade já constituída” (André, 2001, p. 29). Freud (1905/1990) evidencia a condição de enfrentamento, na puberdade, com as intensidades tanto advindas do corpo biológico quanto das excitações psíquicas.

Outro aspecto destacado nesse texto freudiano de $1905 \mathrm{diz}$ respeito ao processo de maturação sexual, o qual contribui e está a serviço da construção da barreira contra o incesto. Nesse sentido, é evidente que "o que é proibido, para a criança, na vivência edípica, é a obtenção de prazer sexual para com seu objeto de amor incestuoso" (Falcão; Veras; Macedo, 2002b, p. 93-94). Essa conflitiva referente à interdição das figuras parentais como objetos de escolha amorosa se reedita na adolescência. É somente a partir da superação 
e da renúncia às fantasias incestuosas que se abre a possibilidade de aquisição de uma sexualidade adulta. Nesse sentido, Vilutis (2000) refere que, na adolescência, o drama edípico ganha intensidade, uma vez que o jovem possui um corpo que, ao menos potencialmente e diferentemente do corpo infantil, é capaz de atos. A volta do que fora recalcado na primeira infância se dá com tamanha intensidade que, somada às aquisições físicas que potencializam ao ato, atemorizam o jovem adolescente. Tais ideias são desenvolvidas por Freud (1939 [1934-38]/1990) em seu texto Moisés e o monoteísmo, ao referir o quanto as intensas transformaçóes da puberdade fragilizam a barreira do recalcamento.

$\mathrm{O}$ acesso à genitalidade, profundamente enlaçado com as temáticas da sexualidade infantil, como bem demarca Freud (1905/1990), confere ao corpo o estatuto de um corpo adulto com direito ao prazer genital no encontro com o outro. Porém, na adolescência, podem surgir manifestações que explicitam dificuldades e fragilidades no processo de metabolização e simbolização dessas intensidades. Pode-se, portanto, observar algumas linguagens específicas que aludem a um fracasso no complexo processo de apropriação da condição da adultez. Assim, a partir de propostas de ampliação das ideias sobre as temáticas da adolescência e destacando a ideia da necessidade e, até mesmo, da imposição de um trabalho psíquico diante das novas aquisições, pode-se eleger o corpo na adolescência como território de expressão dessas demandas. Tal proposição permite considerar o corpo como um espaço privilegiado, no qual as desacomodações da adolescência se expressam e se impõem, não deixando dúvidas sobre a importância das marcas corporais no trabalho de enfrentamento com intensidades psíquicas nessa idade da vida.

O corpo ocupa um lugar de destaque sempre que é abordada a adolescência. Nesse sentido, o corpo adolescente evidencia manifestações da mudança e explicita diferenças concretas e psíquicas em relação à infância, constituindose em um território privilegiado de expressão.

No período da adolescência, o espaço corporal é tomado pelas intensas modificaçóes biológicas e psíquicas que se equiparam a uma vivência de invasão. $\mathrm{O}$ corpo adolescente passa a ser cenário de modificações diante das quais se efetivarão enlaces e desenlaces. Nele as desacomodaçôes são visíveis. Nesse sentido, a "escuta" de algumas dessas linguagens da adolescência implica olhar para o que se expressa via corpo nesse trabalho psíquico de elaboração do excesso. Com base no conceito de dor psíquica, pode-se considerar ser esta provocada pelo excesso que inunda o psiquismo. Como, na adolescência, é inegável a presença de excitações, cuja intensidade pode ser incrementada no fracasso nos recursos de metabolização psíquica, esse excesso de excitação pode 
ser comparado ao desprazer próprio da dor corporal (Dockhorn; Macedo; Werlang, 2007). As marcas corporais na adolescência, quando no contexto do excesso, surgem como expressão da impossibilidade de simbolização.

\section{Marcas corporais: tatuagens e body-piercingscomo(im)possibilidades de simbolização}

$\mathrm{Na}$ desacomodação provocada pela adolescência, encontra-se um sujeito que se vê diante da exigência de processar psiquicamente um excesso que ora o invade desde fora e ora o ataca desde dentro. Mesmo não contando mais com os recursos da onipotência infantil, as ferramentas que usa parecem, por vezes, terem sido forjadas desse mesmo material. No corpo erógeno, o excesso encontra formas de descarga, mas não necessariamente formas de elaboração. $\mathrm{Na}$ tentativa de evitar deparar com a própria dor psíquica, utiliza-se de condutas cujo excesso choca, atemoriza e paralisa, deixando ao encargo do outro o que evita reconhecer ou tem dificuldade de elaborar em si mesmo.

Tomando como ponto de partida a concepção da adolescência como um tempo que traz o enfrentamento com questões da sexualidade, as marcas na pele são pensadas como um recurso usado no intuito de fazer frente ao excessivo da pulsão. Assim, é proposta uma leitura do uso de tatuagens e piercings circunscrita ao contexto adolescente com o intuito de enfatizar que esse ato no corpo ocorre simultaneamente às intensas transformações da adolescência. Dessa forma, esses acontecimentos são abordados, privilegiando-se o momento em que ocorrem e buscando compreender o que querem comunicar.

A origem da palavra tatuagem vem de uma língua antiga do Taiti, onde essa prática foi denominada como tatan, que significa ato de desenhar (Reisfeld, 2004). São exploradas, neste artigo, as tatuagens permanentes, aquelas em que substâncias corantes são introduzidas sob a epiderme através da perfuração para fazer uma marca, desenhos, símbolos, entre outros. Nesse sentido, destaca-se que a tatuagem não é, unicamente, um desenho, uma pintura, um adorno, mas também, e, prioritariamente, uma marca única e definitiva. Pelento (1999) destaca que a tatuagem pode, em algumas ocasióes, "transmitir uma mensagem a ser decifrada” (p. 286).

As tatuagens, os piercings e as mutilações tinham diferentes funçōes conforme a cultura, mas, de modo geral, eram usados como símbolo de pertença a uma tribo, amuleto de proteção ou símbolo de iniciação e reconhecimento social. A partir do cristianismo da Idade Média, essas práticas passaram a ser vistas como mutilação do corpo, caracterizando aqueles que estavam à margem da sociedade e que se diferenciavam da imagem de Deus. Essas práticas passam, 
então, a ser proibidas. Todavia, o corpo marcado volta ao cenário a partir do final do século XIX por meio de marinheiros, circenses, prostitutas, prisioneiros, homossexuais, que buscavam, principalmente, um traço que os diferenciasse. Portanto, além dos elementos psíquicos, as manifestações corporais relacionam-se com elementos culturais. Percebe-se a influência da cultura como correponsável pelas formas de subjetivação de cada tempo (Reisfeld, 1999).

Em referência à proposta freudiana a respeito dos efeitos da civilização na condição humana, desenvolvida no texto Mal-estar na civilização, de 1930, tem-se questionado qual é o mal-estar da atualidade? Para Dunker e Neto (2004), "a sociedade pós-moderna continua centrada no eu [como a moderna], mas a problemática narcísica desloca-se para a imagem dos objetos" (p. 58). Destacam ainda os autores que essa ênfase na exterioridade faz-se notar pelas patologias da ação (tentativas de suicídio, delinquência, vandalismo) e do corporal (patologias psicossomáticas, anorexias, bulimias). Assim, o malestar da atualidade atinge, principalmente, o corpo, tendo em vista que os processos psíquicos de simbolização estão, cada vez mais, escassos.

Nesse contexto, os processos identificatórios atrelam-se à imagem. As tatuagens passaram a ser buscadas como possibilidades de constituição de uma identidade, como bem enfatizam Dunker e Neto (2004) ao sintetizarem a "máxima" da atualidade: faço, logo sou. Dessa maneira, o uso de tatuagens e piercings, embora pareça evocar práticas indígenas, encontra-se distanciado do caráter tribal. $\mathrm{Na}$ atualidade, são observadas multiplicação e diversidade nessas práticas, especialmente entre adolescentes e adultos jovens, como uma maneira de imprimir, por meio de uma marca corpórea, sua singularidade no cenário contemporâneo. Almeida (2001) constata a escassez de recursos imaginativos em comparação com o predomínio da materialidade dos atos e das açôes no mundo dos tatuados. No âmbito desse universo, segundo a autora, a verbalização e a ênfase na narrativa são recursos escassos. A autora destaca o privilégio que a sociedade atual dá ao tempo presente e ao rápido consumo, em busca de uma felicidade instantânea que fica traduzida em experiências bastante intensas, porém, superficiais. Nesse contexto atual, há pouco espaço para o privado e para o reflexivo. Dessa forma, a pele, o corpo, especialmente o corpo adolescente, configura-se como um espaço privilegiado para marcar graficamente uma subjetividade orientada pela estetização.

$\mathrm{Na}$ adolescência, momento da vida no qual mudanças fundamentais ocorrem, encontram-se as tatuagens, marcas duradouras que são feitas na pele. As transformaçôes corporais dão ao adolescente a sensação de descontrole que pode levá-lo à busca por uma tatuagem como sinal de controle e poder sobre 
os limites de sua própria pele (Pelento, 1999).

Reisfeld (2004) propõe que a tatuagem na adolescência pode relacionar-se à elaboração de lutos e também à temática da identidade. Resgatando um olhar para a adolescência que enfatiza a ocorrência de lutos, a autora refere o luto pelo corpo infantil como um importante luto a ser elaborado. Aponta ainda a autora que "a tatuagem comporta um forte sentimento de apropriação do corpo" (p. 69), em um contexto em que as mudanças físicas são intensas e o crescimento pode ser assimétrico. A escassez de elaboração psíquica da nascente representação do corpo adulto pode levar o adolescente a um ato concreto na pele. Evidencia-se a relevância da qualidade do trabalho psíquico exigido do adolescente nessas demandas.

A adolescência é uma etapa em que a ressignificação da identidade está em questão, assim cabe ressaltar que, muitas vezes, a tatuagem pode ser uma forma de expressar condutas de autoafirmação por parte do adolescente. Além disso, a busca pelo pertencimento no grupo de iguais revela a importância na adolescência da identificação a objetos exogâmicos. Nesses movimentos identificatórios do adolescente, Dunker e Neto (2004) consideram que existe, paradoxalmente, a busca por uma identidade compartilhada e singular, uma vez que procuram simultaneamente um traço unificador ao grupo e único. Ou seja, o adolescente quer ser igual a todos e ao mesmo tempo diferente.

A tatuagem - símbolo de atividade e independência - é acompanhada por uma fantasia inconsciente de entrega a uma autoridade (o tatuador) que marca esse corpo, transformando-a em uma espécie de ritual de passagem à condição adulta (Reisfeld, 1999; 2004). Pode-se considerar que a aparente contradição entre independência e entrega no ato de tatuar-se parece explicitar a alternância de recursos usados nas demandas psíquicas da adolescência. Mesmo que não se tenha como objetivo circunscrever a dinâmica da adolescência a um trabalho de luto, conforme referido anteriormente, é inegável que a oscilação de recursos psíquicos dos quais o adolescente lança mão também refletem um movimento regressivo às modalidades de dependência da infância. Muitas vezes, os amigos passam a exercer um papel de poder outrora delegado às figuras parentais. E, como bem destaca Laufer (1998), a modalidade de escolha de amigos é um dos indicadores de saúde psíquica do adolescente.

Reisfeld (2004) aborda a necessidade de diferenciar aqueles adolescentes que têm tatuagens daqueles que são suas tatuagens. Os jovens que têm tatuagens podem ser vistos dentro de uma esfera neurótica. Esses adolescentes têm uma ou algumas tatuagens, as quais, geralmente, refletem temáticas edípicas e seus lutos concomitantes. Dessa forma, a eleição por um desenho tem um 
significado simbólico e inconsciente, sendo a escolha sobredeterminada por fatores que os próprios adolescentes desconhecem. Além disso, nesse grupo de jovens, percebe-se a presença de um critério de realidade, em que o local da pele a ser tatuado não o limitará em seu futuro meio de trabalho. Comumente, estão conscientes de que podem sofrer preconceitos e, por isso, ao tatuaremse, procuram um local do corpo que possa ser escondido por roupas. Em contrapartida, ao referir adolescentes que são suas tatuagens, a autora considera tratar-se de

um grupo constituído por jovens com potencial de risco aditivo que convertem a tatuagem em hábito com características semelhantes a qualquer tipo de adição: a necessidade por tatuarse, certo estado de desespero quando não se satisfaz, dependência e restrição de interesses, podendo em casos extremos terminar com o corpo coberto por tatuagens (Reisfeld, 2004, p. 73).

Dando sequência à leitura das tatuagens no contexto do excesso, Almeida (2001) considera que o sujeito pode encontrar, na prática da tatuagem, o que nomeou como a consistência de uma espécie de selo, como se o sujeito dissesse: tatuei-me, agora eu sou. As tatuagens feitas em série podem apontar para o esvaziamento da representação psíquica e do processo de elaboração que se impóem na passagem adolescente. A busca por tatuagens na adolescência pode ser a primeira de muitas outras que virão, podendo vir a ser uma compulsão por tatuagens, em que "a primeira tatuagem parece ter se convertido em um disparador de conflitos psíquicos mais severos" (Reisfeld, 2004, p. 117). Nessas situaçóes, predomina a necessidade de marcar a pele em detrimento de qualquer motivação por um desenho escolhido e seu significado simbólico. Ao estudar a dinâmica presente no ato de tatuar-se, Almeida (2001) verificou que, muitas vezes, este é precedido por uma explosão de vontade que não permite o movimento reflexivo de escolha. Considera a autora que, em muitos jovens, encontra-se ausente o processo do pensar, predominando o imediatismo.

As tatuagens em série podem, segundo Reisfeld (1999; 2004) indicar, também, uma tentativa de historização. A pele é a superfície na qual poderão ser projetadas uma ampla gama de estados afetivos, fantasias e conflitos inconscientes. $\mathrm{Na}$ carência de recursos psíquicos para conter a excitação psíquica, a pele constitui-se em um espaço delimitado, no qual se podem depositar afetos. Essa tentativa de conter algum conteúdo psíquico na pele parece estar a serviço de uma defesa contra vivências precoces de fragmentação. Frequentemente, as pessoas que têm múltiplas tatuagens precisam inscrever na pele as vivências emocionais significativas. Tal fato reafirma o empobrecimento da capacidade simbólica. Quando não há um trabalho psíquico nas demandas 
de elaboração de uma situação, marcar a pele pode ser uma tentativa de ligação. Nesse sentido, a tatuagem tem a conotação de um operador psíquico necessário, que poderá viabilizar (e, às vezes, inviabilizar) o processo de simbolização.

$\mathrm{O}$ ato de se tatuar, acrescido dessa característica aditiva, está longe de ser uma prática vinculada à moda ou à imitação grupal, pois parece ter se convertido em uma forma específica para construção de uma identidade diferenciada, marcada na própria pele. Essa nova identidade vem acompanhada de novas escolhas que giram em torno das tatuagens, ou seja, seus amigos têm tatuagens ou são tatuadores, frequentam lugares onde tatuagens são feitas e planejam futuras marcas. Assim, formam-se grupos, nos quais os elos entre os adolescentes são as tatuagens. A busca pela modificação drástica da imagem corporal, por vezes, choca e agride o olhar alheio. Esse corpo-imagem parece clamar pelo olhar do outro. Nesse contexto, as tatuagens surgem como marcas corporais que parecem estar a serviço de denunciar o excesso que não pode ser simbolizado e inscrito psiquicamente.

Os piercings, assim como as tatuagens, estão cada vez mais presentes no contexto adolescente. A palavra piercing vem da língua inglesa e é derivada do verbo pierce, que significa "perfurar" (Kernerman, 1997, p. 389). Então, referir os piercings é referir perfurações na pele para que se possa introduzir uma espécie de brinco em diversos locais do corpo, como no umbigo, sobrancelha, língua, entre outros. Assim como a tatuagem, é também uma marca no corpo que perfura a pele e causa dor, embora o piercing, como pode ser removido, não apresente o mesmo caráter permanente da tatuagem.

Os piercings vêm sendo cada vez mais usados por adolescentes, tanto do sexo feminino quanto do masculino. Para os jovens, o uso desse adorno parece incluí-los em um grupo que tem algum traço que os diferencia dos adultos (seus pais). Com isso, pode-se pensar, também, em uma tentativa de apropriar-se do próprio corpo, fazendo com este o que desejam. Existem jovens que fazem uso de piercings como um adorno com o objetivo de chamar a atenção do outro, ou seja, querem ser vistos. Por outro lado, existem jovens com inúmeras perfurações, em semelhança às tatuagens em série. Nesses casos, não é incomum o corpo coberto por tatuagens e piercings. A partir de depoimentos de pessoas adeptas a essas práticas, Maia (2003) identificou que as imagens das tatuagens e os piercings eram nomeadas na terceira pessoa. Assim, o piercing passa a ser "ele", dando ideia de um outro cuidador do sujeito. Cabe destacar o cuidado na interpretação do recurso ao piercing como uma forma de expressão da adolescência. Diferente da tatuagem, ele pode, por ser removível, fazer-se presente mais como adorno transitório do que como instrumento de inscrição na ausência de recursos psíquicos. Porém, o 
caráter de excesso no uso, tanto da tatuagem quanto do piercing, exige uma reflexão a respeito de seu significado, levando em conta a singularidade da história de vida de seu portador.

Alertando para o fato de que essas práticas corporais atendem a aspectos primários da estruturação do psiquismo, Maia (2003) destaca que "as práticas corporais, como a colocação de piercings, tatuagens e escarificações, trazem às pessoas que as praticam sentimentos de autoproteção, de apropriação de uma identidade, de reapropriação do próprio corpo, de autoconfiança, de um corpo que antes parecia não existir" (p. 65). Ao mesmo tempo, a autora enfatiza que é preciso ter cautela ao analisar a estetização da cultura contemporânea.

As marcas no corpo na adolescência evidenciam que este é um meio pelo qual é possível expressar faltas e excessos, comportando, assim, uma linguagem particular desse momento. É necessária a disponibilidade de um olhar atento às novas manifestações no corpo adolescente para que, assim, seja possível entender os pontos de enlace e desenlace entre o que é da ordem do individual e o que é da ordem da cultura em que estão inseridos. Essas considerações se estendem tanto às possibilidades de interpretação do uso de tatuagem quanto de piercings, assim como às diversas modalidades de expressão que o corpo adolescente pode comportar.

\section{Considerações finais}

Dessa forma, a partir da temática referente ao uso de tatuagens e piercings, é possível refletir sobre a inserção do corpo na problemática adolescente. Percebe-se a importância de um olhar atento ao uso desses adornos e marcas no que diz respeito à singularidade que têm para cada adolescente. Longe de defender um olhar preconceituoso, este artigo teve o intuito de chamar atenção para as formas de expressão daquilo que denuncia um fracasso psíquico de metabolizar as intensidades psíquicas próprias do tempo da adolescência.

Em uma época na qual a imagem ganha importância e sob a qual se escondem muitas formas de padecimento, cabe destacar a importância de um olhar atento às diversas formas de expressão da adolescência. As questóes culturais não podem ser deixadas à margem do intenso trabalho de ressignificação que a adolescência impõe. A fragmentação identitária assim como a condição de desamparo experimentada pelos jovens podem estar denunciadas nas marcas corporais. Ao chocar pelo aspecto visual, desconsidera-se o que há de dor psíquica escondida sob uma pele tatuada e carregada de perfurações.

Não se pode, ao escolher a Psicanálise co-mo recurso de compreensão da complexidade desses fenômenos, perder de vista que cada manifestação 
adquire significado a partir da singularidade presente em cada tatuagem, em cada piercing, ou seja, em cada história de vida de um adolescente. Eis que, por meio do excesso presente nessas marcas corporais, apresenta-se, em cada sujeito, uma singular forma de expressão, na qual se pode, respeitosamente, escutar o que não fala, mas comunica.

\section{Referências}

Aberastury, A. \& Knobel, M. (1992). Adolescência normal: um enfoque psicanalítico. Porto Alegre: Artes Médicas.

Almeida, M. I. M. (2001). Tatuagem e subjetividade: reflexões em torno do imaginário da epiderme. Interseçôes: Revista de Estudos Interdisciplinares, 3 (1), 91-109.

André, J. (2001). Feminilidade adolescente. In: Cardoso, M. (Org.). Adolescência: reflexões psicanalíticas. (pp. 29-39). Rio de Janeiro: NAU.

Dunker, C. \& Neto, F. (2004). O ineditismo na adolescência: originalidade, igualdade, repetição. Revista Latino-americana de Psicopatologia Fundamental, 7 (3), 56-66.

Dockhorn, C. N. B. F., Macedo, M. M. K. \& Werlang, B. G. (2007). Desamparo e dor psíquica na escuta da Psicanálise. Revista Barbarói, 27 (2), $25-42$.

Falcão, C. N. B., Krug, J. S. \& Macedo, M. M. K. (2002a). O corpo como expressão do enigmático. In: Macedo, M. M. K. (org.). Neurose: leituras psicanalíticas. (pp. 155-182). Porto Alegre: Edipucrs.

Falcão, C. N. B., Veras, J. F. \& Macedo, M. M. K., M. (2002b). Destinos do Édipo, destinos do sujeito. In: Macedo, M. M. K. (Org.). Neurose: leituras psicanalíticas. (pp. 85-116). Porto Alegre: Edipucrs.

Ferreira, B. H. (1975). Novo dicionário da língua portuguesa. Rio de Janeiro: Nova Fronteira.

Freud, S. (1990). As neuropsicoses de defesa. In: Edição standard das obras psicológicas completas de Sigmund Freud: v. III. (pp. 51-72). Rio de Janeiro: Imago. (Texto original publicado em 1984). 
Freud, S. (1990). Três ensaios sobre a teoria da sexualidade. In: Edição standard das obras psicológicas completas de Sigmund Freud: v. VII. (pp. 118-217). Rio de Janeiro: Imago. (Texto original publicado em 1905).

Freud, S. (1990). A concepção psicanalítica da perturbação psicogênica da visão. In: Edição standard das obras psicológicas completas de Sigmund Freud: v. XI. (pp. 197-206). Rio de Janeiro: Imago. (Texto original publicado em 1910).

Freud, S. (1990). Os instintos e suas vicissitudes. In: Edição standard das obras psicológicas completas de Sigmund Freud: v. XIV. (pp. 137-168). Rio de Janeiro: Imago. (Texto original publicado em 1915).

Freud, S. (1990). Luto e melancolia. In: Edição standard das obras psicológicas completas de Sigmund Freud: v. XIV. (pp. 275-291). Rio de Janeiro: Imago. (Texto original publicado em 1917).

Freud, S. (1990). Mal-estar na civilização. In: Edição standard das obras psicológicas completas de Sigmund Freud: v. XXI. (pp. 81-171). Rio de Janeiro: Imago. (Texto original publicado em 1930).

Freud, S. (1990). Moises e o monoteísmo. In: Edição standard das obras psicológicas completas de Sigmund Freud: v. XXIII. (pp. 16-245). Rio de Janeiro: Imago. (Texto original publicado em 1939 [1934-38]).

Freud, S. (1990). Projeto para uma Psicologia científica. In: Edição standard das obras psicológicas completas de Sigmund Freud: v. I. (pp. 381-529). Rio de Janeiro: Imago. (Texto original publicado em 1950 [1895]).

Garcia-Roza, L. A. (1999). Introdução à metapsicologia freudiana: artigos de metapsicologia: v. III. Rio de Janeiro: Zahar.

Keil, I. \& Tiburi, M. (2004). Diálogos sobre o corpo. Porto Alegre: Escritos.

Kernerman, L. (1997). Password: English dictionary for speakers of Portuguese. São Paulo: Martins Fontes.

Laufer, M. (1998). El adolescente suicida. Madrid: Editorial Biblioteca Nueva.

Maia, M. S. (2003). O ideário contemporâneo de subjetividade e os modos de subjetivação. In: Maia, M. S. Extremos da alma: dor e trauma na atualidade e clínica psicanalitica. (pp. 63-90). Rio de Janeiro: Garamond. 
Pelento, M. L. (1999). Los tatuages como marcas: ruptura de los lazos sociales y su incidencia en la construción de la subjetividad individual y social. Revista de Psicoanálisis, 56 (2), 283-297.

Rassial, J-J. (1995). A passagem adolescente: da família ao laço social. Porto Alegre: Artes e Ofícios.

Reisfeld, S. (1999). El cuerpo tatuado: una mirada sobre los adolescentes con múltiples tatuages. Revista de Psicoanálisis, 56 (2), 298-307.

Reisfeld, S. (2004). Tatuages: una mirada psicoanalítica. Buenos Aires: Paidós.

Urribarri, R. (2003). Sobre adolescência, luto e a posteriori. Revista de Psicanálise da Sociedade Psicanalítica de Porto Alegre, 10 (1), 47-70.

Viglietti, G. V. (2000). Duelos y adolescencia. In: Asociación Psicoanalítca del Uruguay (org.). Anais do I Congresso Uruguayo de Psicoanálisis y II Jornada Cientifica, Tomo II. (pp. 47-52). Montevideo: APU.

Villutis, M. I. (2000). Dor psíquica e adolescência. In: Fuks, L. \& Ferraz, F. (Org.). A clínica conta histórias. (pp. 69-78). São Paulo: Escuta.

Psicanálise da Sociedade Psicanalítica de Porto Alegre, 10 (1), 47-70.

Viglietti, G. V. (2000). Duelos y adolescencia. In: Asociación Psicoanalítca del Uruguay (org.). Anais do I Congresso Uruguayo de Psicoanálisis y II Jornada Cientifica, Tomo II. (pp. 47-52). Montevideo: APU.

Villutis, M. I. (2000). Dor psíquica e adolescência. In: Fuks, L. \& Ferraz, F. (Org.). A clínica conta histórias. (pp. 69-78). São Paulo: Escuta. 